\title{
Review: 7.7 to 12.9 units of alcohol per week is the level of alcohol consumption at which mortality is the lowest in men
}

\author{
White IR. The level of alcohol consumption at which all-cause mortality is least. J Clin Epidemiol 1999 Oct;52:967-75.
}

QUESTION: What is the level of alcohol consumption at which mortality is the lowest (nadir)?

\section{Data sources}

Studies were identified in Medline using the key words alcohol, drinking, beer, wine, spirits, mortality, death, and coronary heart disease. References of recent reviews were scanned and experts in the field were contacted.

\section{Study selection}

Studies were selected if they were cohort studies in industrialised countries that related all cause mortality to alcohol consumption. Studies were excluded if they did not report mortality for men and women separately or if they reported $<3$ levels of alcohol consumption.

\section{Data extraction}

Relative risks of all cause mortality, adjusted for age, and where possible, other risk factors including socioeconomic status, education, smoking, and physical health, were extracted for each level of alcohol consumption in each study. Amounts of alcohol were converted to units per week ( 1 unit of alcohol $=9 \mathrm{~g}$ ).

\section{Main results}

21 articles reporting 20 studies (1 210545 participants) were included. 60224 deaths among men (13\%) and 74824 deaths among women $(10 \%)$ occurred. In men, 12 of 19 estimated nadirs were $<10$ units/week and 3 were $>20$ units/week. In women, 4 of 8 estimated nadirs were $<5$ units/week and 1 was $>10$ units/week. Nadirs varied between countries but not within countries. Nadirs for men and women pooled at the country level are in the table. Nadirs were estimated for men from 10 US studies and 3 UK studies. 6 other countries only contributed 1 nadir each. Nadirs were estimated for women from 7 US studies and only 1 non-US nadir was contributed. When adjustment was made for smoking, blood pressure, exclusion of participants with baseline coronary heart disease, and exclusion of ex-drinkers, the nadir did not change by more than 3 units/ week. 6 studies that provided results by age group showed no relation between nadir and age; the pooled estimated nadirs were appropriate for ages $50-80$ years.

\section{Conclusion}

The level of alcohol consumption at which mortality is the lowest (nadir) is between 7.7 and 12.9 units of alcohol per week in men and is 2.9 units of alcohol per week in women, for ages 50-80 years (table).

Level of alcohol consumption at which mortality is the lowest (nadir)

\begin{tabular}{lll} 
Group & $\begin{array}{l}\text { Number of } \\
\text { studies }\end{array}$ & $\begin{array}{l}\text { Pooled nadir in units of } \\
\text { alcohol/week }(95 \% \mathrm{CI})\end{array}$ \\
US men & 10 & $7.7(6.4$ to 9.1$)$ \\
\hline UK men & 3 & $12.9(10.8$ to 15.1$)$ \\
\hline US women & 7 & $2.9(2.0$ to 4.0$)$ \\
\hline
\end{tabular}

\section{COMMENTARY}

The alcohol industry and others have long promoted the idea of an "optimal" level of alcohol consumption at which there is a relative reduction in overall mortality. White suggests that it is possible to estimate the safest levels of consumption, at least for men, in the 50-80 year age group in the US and UK. One methodological problem with this review is that it combines studies using different measures of alcohol intake. Weekly consumption may not be the best measure to study mortality. For example, a study done in Russia showed that a pattern of weekend binges may predict alcohol related deaths. ${ }^{1}$ A life history perspective often helps because people at risk of alcohol related deaths vary their consumption over time. ${ }^{2}$ In practice, it seems that questions on participants' "usual consumption" do not produce the same result as keeping a drink diary for a specific week.

Despite these methodological issues, most studies produced a U-shaped risk curve. In other words, participants drinking a moderate amount of alcohol per week have lower mortality rates than either abstainers or those drinking higher levels of alcohol. 2 studies with younger participants $(<30 \mathrm{y})$, however, did not show this U-shaped curve. Instead, these studies showed a monotonic increase in mortality as intake rose, similar to a more recent study of UK men. ${ }^{3}$

Practitioners judging the potential for a protective or harmful action need to consider more than the dose response relation between alcohol and mortality. Alcohol consumption can also negatively affect the patient in other ways including reducing participation in health screening, ${ }^{4}$ increasing life stress, and reducing social support ${ }^{5}$ in ways that predict "sick" old age.

Woody Caan, MA, DPhil Society of Health Education and Health Promotion Specialists Cambridge, $U K$

1 Chenet L, McKee M, Leon D, et al. Alcohol and cardiovascular mortality in Moscow; new evidence of a causal association. J Epidemiol Community Health 1998; 52:772-4.

2 Finney JW, Moos RH, Timko C. The course of treated and untreated substance use disorders: remission and resolution, relapse and mortality. In: McCrady BS, Epstein EE, editors. Addictions: a comprehensive guidebook. New York: Oxford University Press, 1999;30-49.

3 Hart CL, Smith CD, Hole DJ, et al. Alcohol consumption and mortality from all causes, coronary heart disease, and stroke: results from a prospective cohort study of Scottish men with 21 years of follow up. BMJ 1999;318:1725-9.

4 Cryer PC, Jenkins LM, Cook AC, et al. The use of acute and preventative medical services by a general population: relationship to alcohol consumption. Addiction 1999;94:1523-32.

5 Vaillant GE. Lessons learned from living. Scientific American Presents 1999;10:32-7.
Source of funding: no external funding.

For correspondence: $\mathrm{Mr}$ IR White, Medical Statistics Unit, London School of Hygiene and Tropical Medicine, Keppel Street, London +44 (0)20 76372853. 